Journal of Applied Pharmaceutical Science Vol. 5 (10), pp. 059-066, October, 2015

Available online at http://www.japsonline.com

DOI: $10.7324 / \mathrm{JAPS} .2015 .501011$

ISSN 2231-3354 (cc) BY-NC-sA

\title{
Isolation and Identification of Potential Antineoplastic Bioactive Phenolic Compounds in Malaysian Honeys
}

\author{
Norjihada Izzah Ismail ${ }^{1}$, Mohammed Rafiq Abdul Kadir ${ }^{1 *}$, Razauden Mohamed Zulkifli \\ ${ }^{1}$ Medical Implant Technology Group, Faculty of Biosciences and Medical Engineering, Universiti Teknologi Malaysia, Skudai, 81310, Johor, Malaysia. \\ ${ }^{2}$ Department of Bioscience and Health Sciences, Faculty of Biosciences and Medical Engineering, Universiti Teknologi Malaysia, Skudai, 81310, Johor, \\ Malaysia.
}

\section{ARTICLE INFO \\ Article history: \\ Received on: 21/06/2015 \\ Revised on: 11/07/2015 \\ Accepted on: 04/08/2015 \\ Available online: 28/10/2015}

\section{Key words:}

Honey, flavonoids, phenolic acids, tannins, anticancer, high-performance liquid chromatography (HPLC).

\begin{abstract}
The role of honeys as chemopreventive agents was inferred from their phenolic composition. The present study aims to isolate and identify such phenolic compounds with anticarcinogenic potential from the sugar matrix of Malaysian honeys. Phenolic compounds in Malaysian Acacia, Gelam and Tualang honey samples were isolated using octadecyl (C18) silica solid phase extraction (SPE) technique and identification was performed using highperformance liquid chromatography (HPLC) with diode array detector (DAD). Identification of phenolic compounds was achieved by comparing chromatographic retention times of honey samples with those of authentic standard compounds. HPLC analysis confirmed the presence of anticancer phenolic compounds in all honey samples with considerable variation observed among both different and the same types of honey. Six flavonoids (quercetin, naringenin, kaempferol, rutin, hesperetin, and apigenin), two phenolic acids ( $p$-coumaric acid, and ferulic acid) and two tannins (ellagic acid, and penta- $O$-galloyl- $\beta$-D-glucose [PGG]) were the bioactive anticancer compounds identified. The presence of PGG in Malaysian honey was described for the first time. This study concludes that these three types of Malaysian honey possessed anticancer properties at varying degrees. Their potential usage as natural anticancer therapeutic agents with numerous health benefits could be further explored and considered as an alternative for current anticancer drugs.
\end{abstract}

\section{INTRODUCTION}

Honey is a natural product rich in phytochemicals. A phytochemical is a substance derived from a plant source which could be any of various vitamins, minerals or bioactive compounds (Simon, 2002). Previously, honey has been consumed as a dietary supplement or used as a topical aid to cure some ailments. These days, more of its functional properties have been discovered. Evidences from in vitro, in vivo as well as clinical trials have proven that honeys harvested from places all over the world exhibit various therapeutic properties, such as anti-inflammatory, antioxidant, antimicrobial, and antidiabetic effects, with recent highlight placed on its antineoplastic (antiproliferative and anticarcinogenic) activity (Jaganathan and Mandal, 2009; Abubakar et al., 2012; Othman, 2012; Erejuwa et al., 2014). Reported studies have revealed that crude honeys are

\footnotetext{
* Corresponding Author

Faculty of Biosciences and Medical Engineering, Universiti Teknologi Malaysia, Skudai, 81310, Johor, Malaysia.

Email: rafiq@biomedical.utm.my; Tel.: +6075558514
}

promising chemopreventive agents (Swellam et al., 2003; Fauzi et al., 2011; Kadir et al., 2013). These findings have attracted much interest among health practitioners, survival and in-treatment cancer patients, considering the side effects of current cancer drugs and emergence of drug resistance (chemoresistance) as well as radioresistance in cancer treatment that have triggered massive continuous searches for alternative ways in treating cancer patients.

Cancer chemoprevention is defined as the use of natural, synthetic, or biologic chemical agents to reverse, suppress, or prevent carcinogenic progression (Sporn, 1976; Surh, 2003). Cancer is a multistep process that comprises of three key stages: initiation, promotion and progression (Surh, 2003; Fresco et al., 2006; Othman, 2012; Erejuwa et al., 2014). Initiation is the first stage of carcinogenesis, a rapid and irreversible process that is characterized by the accumulation of mutated deoxyribonucleic acid (DNA) upon exposure to carcinogens (cancer-causing agents). Promotion stage, in contrast to initiation stage, is a lengthy process in which mutated (preneoplastic) cells actively proliferate and accumulate. The last stage, progression, is when the cancer cells 
metastasize (disseminate) to distant sites such as tissues and organs through the lymphatic system and bloodstreams (Surh, 2003; Erejuwa et al., 2014). Therefore, cancer chemopreventive agents are substances that could prevent, arrest or reverse the cancer development at various stages. Basically, there are two main categories of chemopreventive agents based on their mechanisms of action-blocking agents and suppressing agents. Blocking agents can impede initiation by either preventing carcinogens from reaching the target sites, from undergoing metabolic activation or from interacting with crucial cellular target molecules such as DNA, ribonucleic acid (RNA) or proteins. Suppressing agents, in turn, inhibit the expression of initiated cells in either the stages of promotion or progression (Surh, 2003; Fresco et al., 2006).

It is postulated that the role of honey as a chemopreventive agent was attributed from its bioactive composition, particularly the phenolic compounds (polyphenols) (Jaganathan and Mandal, 2009; Abubakar et al., 2012; Erejuwa et al., 2014). As a phytochemical-rich product, honey possesses a range of phenolic compounds, whose source originates from where bees forage for nectars and pollens. This natural phenomenon is one of the key factors that differentiate one type of honey from another, and even from one hive to another in the same location. It has been reported that honey comprises of phenolic acids and flavonoids as the major phenolic compounds (Jaganathan and Mandal, 2009; Abubakar et al., 2012). Phenolic acids namely ferulic, caffeic, $p$-coumaric acids and flavonoids including naringenin, hesperetin, apigenin, kaempferol, rutin, chrysin and quercetin are among the polyphenols that are present in honey (Jaganathan and Mandal, 2009; Abubakar et al., 2012; Erejuwa et al., 2014), and have been identified as the promising chemopreventive agents (Fresco et al., 2006; Gao et al., 2006; Alshatwi et al., 2013; Chen et al., 2013; Jaganathan et al., 2013). Tannins such as ellagic acid and penta- $O$-galloyl- $\beta$-D-glucose (PGG) are another class of polyphenols that have been reported to exhibit anticarcinogenic properties as well (Abubakar et al., 2012; Zhang et al., 2009). All these polyphenolic compounds were observed to act through one or more combinations of several mechanisms; either by inducing apoptosis (cell death), arresting cell cycle, inhibiting cell growth and growth factor (GF) expression or through promoting DNA repair mechanism (Surh, 2003; Fresco et al., 2006; Gao et al., 2006; Jaganathan and Mandal, 2009; Zhang et al., 2009; Abubakar et al., 2012; Othman, 2012; Alshatwi et al., 2013; Chen et al., 2013; Jaganathan et al., 2013; Erejuwa et al., 2014). Previously, column chromatography was the most popular method available for compounds separation. In recent years, SPE has been used in many experimental designs and is considered as an acceptable alternative to the conventional column chromatography. Both methods perform the separation (purification) of individual chemical compounds from mixtures of compounds. Both methods have been reportedly utilized in the isolation of honey phenolic compounds. For this purpose, C18 silica membrane disks and non-ionic polymeric Amberlite XAD resins were commonly employed in SPE (Aljadi and Yusoff, 2003;
Michalkiewicz et al., 2008; Hussein et al., 2011; Khalil et al., 2011) and column chromatography (Ferreres et al., 1994; Yao et al., 2003; Kassim et al., 2010), respectively. Similarly, HPLC has been used widely for the separation and characterization of phenolic compounds in the last two decades, where both isocratic and gradient elution have been applied for analyses of phenolic compounds (Stalikas, 2007). Malaysian Tualang and Gelam honeys have been reported to exhibit anticarcinogenic properties against different types of cancer cell lines and in in vivo studies (Fauzi et al., 2011; Abubakar et al., 2012; Wen et al., 2012; Kadir et al., 2013), but limited published data was available for Malaysian Acacia honey. Thus, this work aimed to isolate and identify phenolic compounds with anticarcinogenic potential from the sugar matrix of these three types of Malaysian honeys in order to verify their roles as prospective natural chemopreventive agents.

\section{MATERIALS AND METHODS}

\section{Collection of honey samples}

Three types of Malaysian honeys (Gelam [Melaleuca cajuputi], Acacia [Acacia mangium] and Tualang [multifloral] honeys) were collected starting in December 2012 until February 2013 (Table 1). The locations of honey collection are shown in Figure 1. All seven samples were stored in the dark at room temperature before analysis.

Table 1: Honey samples involved in this study.

\begin{tabular}{clll}
\hline Honey samples $^{\text {a }}$ & Type & Botanical origin & Local name \\
\hline G1 & Monofloral & Melalueca cajuputi & Gelam \\
G2 & Monofloral & Melalueca cajuputi & Gelam \\
T1 & Multiforal & Mixed source & Tualang \\
T2 & Multiforal & Mixed source & Tualang \\
A1 & Monofloral & Acacia mangium & Acacia \\
A2 & Monofloral & Acacia mangium & Acacia \\
A3 & Monofloral & Acacia mangium & Acacia \\
\hline${ }^{a} \mathrm{G}=$ Gelam honey, $\mathrm{T}=$ Tualang honey, A = Acacia honey.
\end{tabular}

\section{Reagents and chemicals}

Analytical grade hydrochloric acid $(\mathrm{HCl})$ (J.T.Baker, PA, USA), analytical grade methanol, HPLC-grade methanol and formic acid (Merck KgaA, Darmstadt, Germany), and ultrapure water (Easypure Barnstead, Thermo Scientific Inc., USA) were used for sample pre-treatment and mobile phase preparation. Seventeen reference standard compounds were purchased for identification of polyphenols in studied honey samples. Naringenin was purchased from Sigma-Aldrich Co. (Steinheim, Germany). Caffeic acid, syringic acid, ellagic acid, $p$-coumaric acid, rutin hydrate, kaempferol, apigenin, quercetin, (-)-catechin, chrysin, trans-cinnamic acid, luteolin, and PGG were purchased from Sigma Chemicals Co. (St. Louis, MO, USA) whereas hesperetin, benzoic acid, and trans-ferulic acid were supplied by Fluka (Buchs, Switzerland).

\section{Isolation of phenolic compounds using solid phase extraction (SPE)}

The extraction was carried out as described by Hussein et al. (2011) with modifications. Five grams of honey sample were 
dissolved in $25 \mathrm{~mL}$ of acidified deionised water (adjusted to $\mathrm{pH} 2$ with diluted $\mathrm{HCl}$ ), stirred for 30 minutes, and filtered using Whatman No. 1 filter paper to remove solid particles. Eight milliliters of methanol and $4 \mathrm{~mL}$ of $0.01 \mathrm{M} \mathrm{HCl}$ were applied sequentially to precondition C18 SPE cartridges (Agilent Bond Elut $\mathrm{C} 18,500 \mathrm{mg}, 6 \mathrm{~mL}$ ). The filtrate was passed through the preconditioned $\mathrm{C} 18$ column and washed with $125 \mathrm{~mL}$ of $0.01 \mathrm{M}$ $\mathrm{HCl}$ to remove sugars. The adsorbed compounds were eluted with methanol $(150 \mathrm{~mL})$ followed by evaporation until a dry state is reached under reduced pressure at $40{ }^{\circ} \mathrm{C}$ using a rotary evaporator with a water bath.

\section{Sample extract and standard compound preparation}

Prior to injection into an HPLC system, the residues were dissolved in HPLC grade methanol $(1 \mathrm{~mL})$, filtered through $0.45 \mu \mathrm{m}$ syringe filters and concentrated to $0.5 \mathrm{~mL}$. The mixtures of seventeen reference standard compounds $(100 \mu \mathrm{g} / \mathrm{mL}$ each), also prepared in HPLC grade methanol were filtered through 0.2 $\mu \mathrm{m}$ syringe filters prior HPLC analysis.

\section{Identification of phenolic compounds using high-performance liquid chromatography (HPLC)}

The chromatographic identification of phenolic compounds of interest was performed on Agilent 1100 series HPLC system (Agilent Technologies, USA) equipped with multichannel diode array detector (G1315B), on-line degasser (G1379A), quatpump (G1311A), autosampler (G1313A), and column heater (G1316A). Instrument control and data analysis were performed using Agilent HPLC Chemstation. The analytical column was a reversed-phase column ZORBAX Eclipse XDBC18 (4.6 mm x 150 mm, $5 \mu \mathrm{m}$, Agilent Technologies, USA). The binary mobile phase consisted of $0.25 \%$ formic acid and $2 \%$ methanol in ultrapure water (solvent A) and 100\% methanol (solvent B), as described by Hussein et al. (2011). Elution from the column was achieved with the following gradient: time $15 \mathrm{~min}$ : $10 \% \mathrm{~B}$; time $18 \mathrm{~min}: 15 \% \mathrm{~B}$; time $20 \mathrm{~min}: 20 \% \mathrm{~B}$; time $23 \mathrm{~min}$ : $30 \% \mathrm{~B}$; time $25 \mathrm{~min}: 35 \% \mathrm{~B}$; time $28 \mathrm{~min}: 40 \% \mathrm{~B}$; time $30 \mathrm{~min}$ : $45 \% \mathrm{~B}$; time $40 \mathrm{~min}: 60 \% \mathrm{~B}$. The final composition was kept constant up to $50 \mathrm{~min}$. Prior to subsequent injection, the system was equilibrated for 10 minutes. The system was operated at temperature, flow rate and an injection volume of $28^{\circ} \mathrm{C}, 1 \mathrm{~mL} / \mathrm{min}$ and $20 \mu \mathrm{L}$, respectively. Detection of phenolic compounds was performed using UV absorption spectra monitoring at $290 \mathrm{~nm}$ and $340 \mathrm{~nm}$. The flavonoids, phenolic acids and tannins were identified by comparing the chromatograms and retention times (RTs) of the analytes with reference standards.

\section{RESULTS}

The phenolic compounds with anticarcinogenic properties identified in seven Malaysian honey samples are presented in Table 2. In this study, two phenolic acids (transferulic and $p$-coumaric acids), six flavonoids (rutin, hesperetin, quercetin, naringenin, kaempferol and apigenin) and two tannins (PGG and ellagic acid) were detected either at $290 \mathrm{~nm}$ and/or 340 $\mathrm{nm}$ wavelengths. Figure 2 depicts the HPLC chromatograms of the analysed Malaysian Gelam, Tualang and Acacia honey samples. Trans-ferulic acid, found in all analysed honey samples, is seen as the most common phenolic compound regardless of honeys' geographical location, botanical origin, and time of collection. Other compounds common to Gelam honey samples (G1 and G2) were hesperetin, kaempferol, and rutin, whereas $p$-coumaric acid was observed in both Tualang honey samples (T1 and T2). Acacia honey samples (A1, A2 and A3) contained naringenin, quercetin, and $p$-coumaric acid as another common polyphenols (Table 2).

From the HPLC chromatograms of three Acacia and two Gelam honey samples, it was shown that monofloral Acacia and Gelam honeys are rich in polyphenols as compared to multifloral Tualang honeys (Figure 2), in which an increasing number of peaks and relatively high peak intensities were observed for these two types of monofloral honeys. The polyphenols detected in this study were mostly in the form of aglycones instead of glycoside conjugates. Interestingly, two out of three Malaysian Acacia honey samples studied (A2 and A3) exhibited the presence of PGG at relatively low concentrations (Figure 2c). The presence of more unidentified peaks, especially in Acacia and Gelam honeys, indicates that more sensitive instruments such as liquid chromatography (LC) coupled with mass spectrometry (MS) is needed to further identify those compounds. Figure 3 depicts chromatograms of authentic standard compounds at both $290 \mathrm{~nm}$ and $340 \mathrm{~nm}$ wavelengths, where some compounds were better detected at $290 \mathrm{~nm}$ and vice versa.

Table 2: Phenolic acids, flavonoids and tannins detected in different types of Malaysian honey samples using HPLC analysis.

\begin{tabular}{|c|c|c|c|c|c|c|}
\hline Compound & RT (min) at $290 \mathrm{~nm}^{\mathrm{a}}$ & SD $^{\mathbf{b}}$ & Sample $^{\mathrm{c}}$ & RT (min) at 340nm ${ }^{a}$ & SD $^{\mathbf{b}}$ & Sample $^{c}$ \\
\hline$p$-Coumaric acid & 26.887 & 0.059 & $\mathrm{G} 1, \mathrm{~T} 1, \mathrm{~T} 2, \mathrm{~A} 2, \mathrm{~A} 3$ & 26.887 & 0.059 & $\mathrm{G} 1, \mathrm{~A} 1, \mathrm{~A} 2, \mathrm{~A} 3$ \\
\hline Ferulic acid & 28.244 & 0.056 & $\mathrm{G} 1, \mathrm{G} 2, \mathrm{~T} 1, \mathrm{~T} 2, \mathrm{~A} 1, \mathrm{~A} 3$ & 28.244 & 0.056 & $\mathrm{~T} 1, \mathrm{~T} 2, \mathrm{~A} 1, \mathrm{~A} 2, \mathrm{~A} 3$ \\
\hline Penta- $O$-galloyl- $\beta$-D-glucose (PGG) & 28.606 & 0.034 & $\mathrm{~A} 2, \mathrm{~A} 3$ & - & - & \\
\hline Rutin & 31.830 & 0.062 & $\mathrm{G} 2, \mathrm{~A} 2$ & 31.830 & 0.062 & $\mathrm{G} 1, \mathrm{G} 2, \mathrm{~A} 1, \mathrm{~A} 2$ \\
\hline Ellagic acid & 32.703 & 0.078 & $\mathrm{~T} 1, \mathrm{~T} 2, \mathrm{~A} 1$ & 32.704 & 0.077 & $\mathrm{G} 1, \mathrm{~A} 1, \mathrm{~A} 3$ \\
\hline Quercetin & 37.144 & 0.100 & $\mathrm{~A} 1, \mathrm{~A} 2$ & 37.143 & 0.098 & $\mathrm{~A} 1, \mathrm{~A} 2, \mathrm{~A} 3$ \\
\hline Naringenin & 37.474 & 0.095 & $\mathrm{G} 1, \mathrm{~T} 1, \mathrm{~A} 1, \mathrm{~A} 2, \mathrm{~A} 3$ & 37.471 & 0.094 & $\mathrm{G} 1, \mathrm{~T} 1, \mathrm{~A} 1, \mathrm{~A} 2, \mathrm{~A} 3$ \\
\hline Hesperetin & 38.575 & 0.091 & $\mathrm{G} 1, \mathrm{G} 2$ & 38.412 & 0.111 & $\mathrm{G} 1, \mathrm{G} 2, \mathrm{~T} 1$ \\
\hline Kaempferol & 40.588 & 0.109 & $\mathrm{G} 1, \mathrm{~T} 2$ & 40.588 & 0.109 & $\mathrm{G} 2, \mathrm{~A} 1, \mathrm{~A} 2$ \\
\hline Apigenin & 41.177 & 0.115 & $\mathrm{G} 1, \mathrm{~T} 1$ & 41.177 & 0.115 & G1 \\
\hline
\end{tabular}

${ }^{\mathrm{a}} \mathrm{RT}=$ retention time, based on mixtures of standard compounds $(100 \mu \mathrm{g} / \mathrm{mL}$ each). Values are mean of duplicate analysis.

${ }^{\mathrm{b}} \mathrm{SD}=$ standard deviation, $(\mathrm{n}=2) .{ }^{\mathrm{c}} \mathrm{G}=$ Gelam honey, $\mathrm{T}=$ Tualang honey, $\mathrm{A}=$ Acacia honey. 
Table 3: Anticarcinogenic mechanisms of action of polyphenols on cancer cells.

\begin{tabular}{|c|c|c|c|}
\hline Cancer research & $\begin{array}{l}\text { Phenolic } \\
\text { compound }^{\text {a }}\end{array}$ & Cell line (cancer) & Action $^{b}$ \\
\hline $\begin{array}{l}\text { Jaganathan et al. } \\
\text { (2013) }\end{array}$ & $\begin{array}{l}p \text {-Coumaric } \\
\text { acid }\end{array}$ & HCT-15 (colon) & Induce apoptosis \\
\hline Chen et al. (2013) & Rutin & $\begin{array}{l}\text { LAN-5 } \\
\text { (neuroblastoma) }\end{array}$ & $\begin{array}{l}\text { G2/M arrest, induce } \\
\text { apoptosis }\end{array}$ \\
\hline Alshatwi et al. (2013) & Hesperetin & $\mathrm{SiHa}$ (cervical) & Induce apoptosis \\
\hline Gao et al. (2006) & Naringenin & $\mathrm{LNCaP}$ (prostate) & DNA repair \\
\hline Hagiwara et al. (2010) & Ellagic acid & HL-60 (leukemia) & Induce apoptosis \\
\hline Hu et al. (2008) & PGG & LNCaP (prostate) & Induce apoptosis \\
\hline Chai et al. (2010) & PGG & MCF-7 (breast) & G1 and S arrest \\
\hline $\begin{array}{l}\text { Gonzalez-Mejia et al. } \\
\text { (2010) }\end{array}$ & Apigenin & THP (leukemia) & Induce apoptosis \\
\hline Bestwick et al. (2007) & Kaempferol & HL-60 (leukemia) & $\begin{array}{l}\text { Cell cycle arrest, } \\
\text { inhibit growth }\end{array}$ \\
\hline Lee et al. (2006) & Quercetin & U937 (leukemia) & $\begin{array}{l}\text { Induce apoptosis, } \\
\text { cell cycle arrest }\end{array}$ \\
\hline Luo et al. (2008) & Quercetin & $\begin{array}{l}\text { OVCAR-3 } \\
\text { (ovarian) }\end{array}$ & $\begin{array}{l}\text { Inhibit VEGF } \\
\text { expression }\end{array}$ \\
\hline Kampa et al. (2004) & Ferulic acid & T47D (breast) & Inhibit growth \\
\hline
\end{tabular}

${ }^{\text {a }} \mathrm{PGG}=$ Penta- $O$-galloyl- $\beta$-D-glucose .

${ }^{\mathrm{b}} \mathrm{VEGF}=$ Vascular endothelial growth factor .

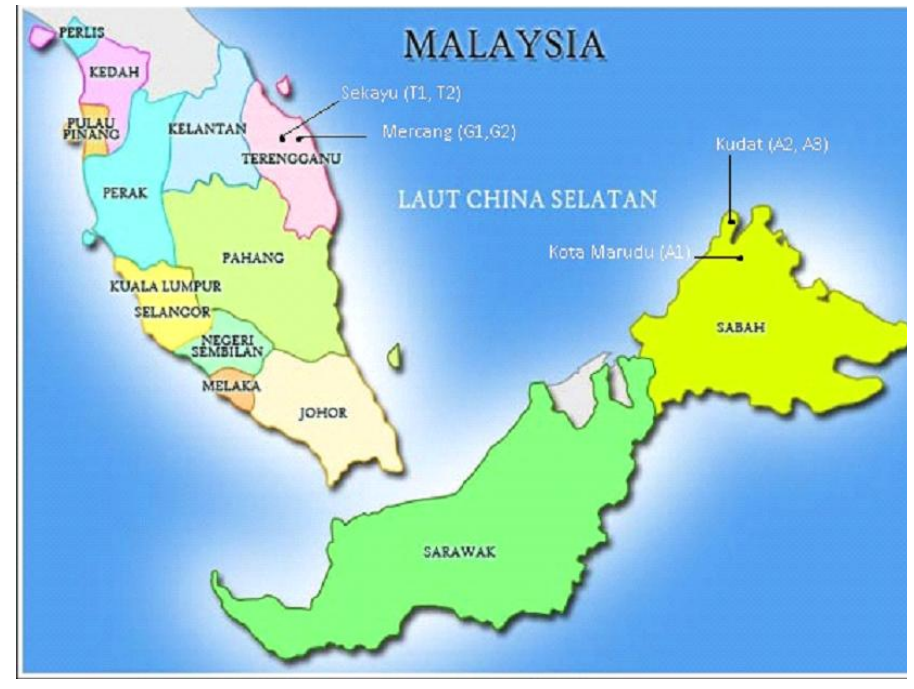

Fig. 1: Location of honey collection.

a
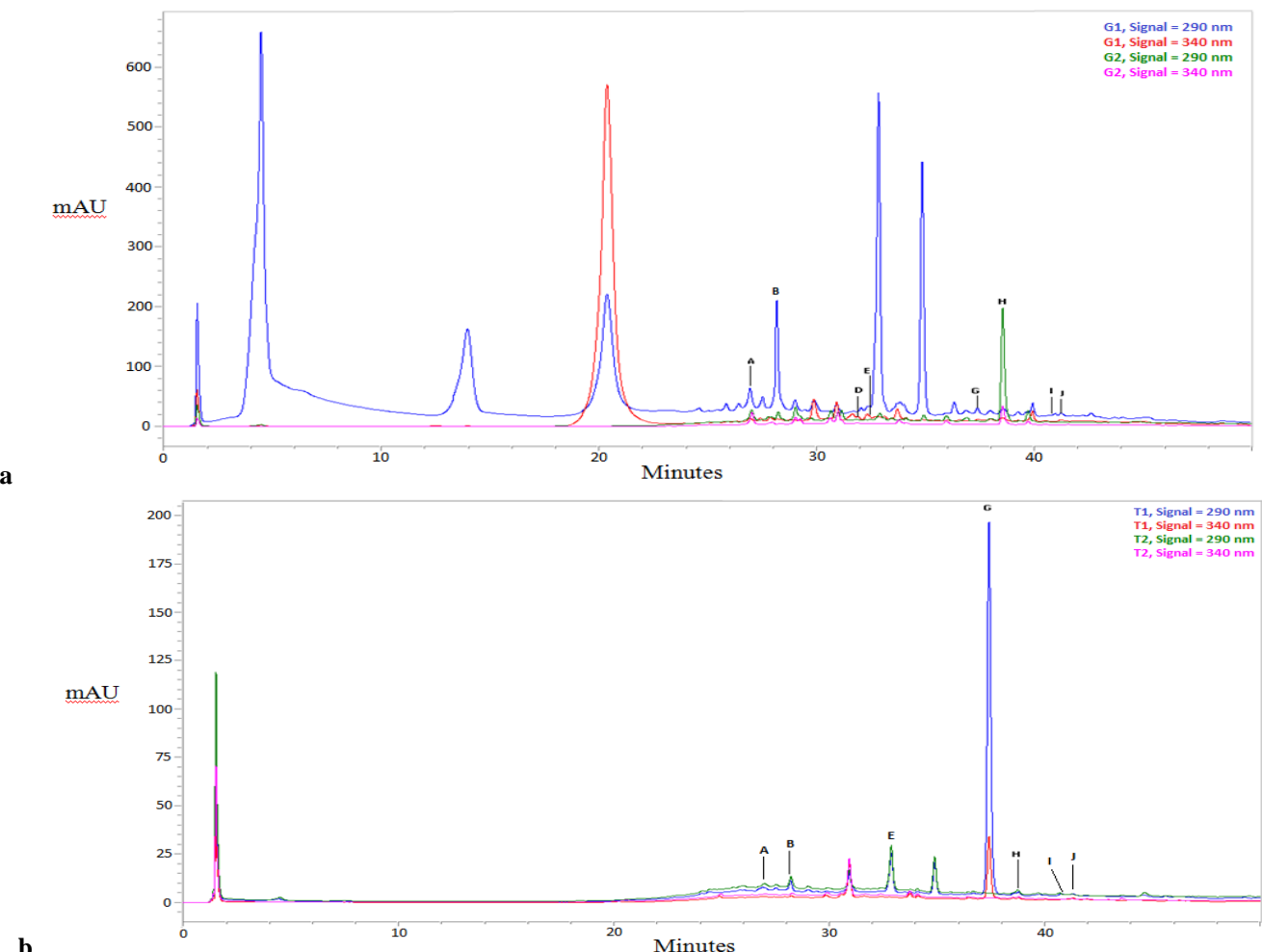

b

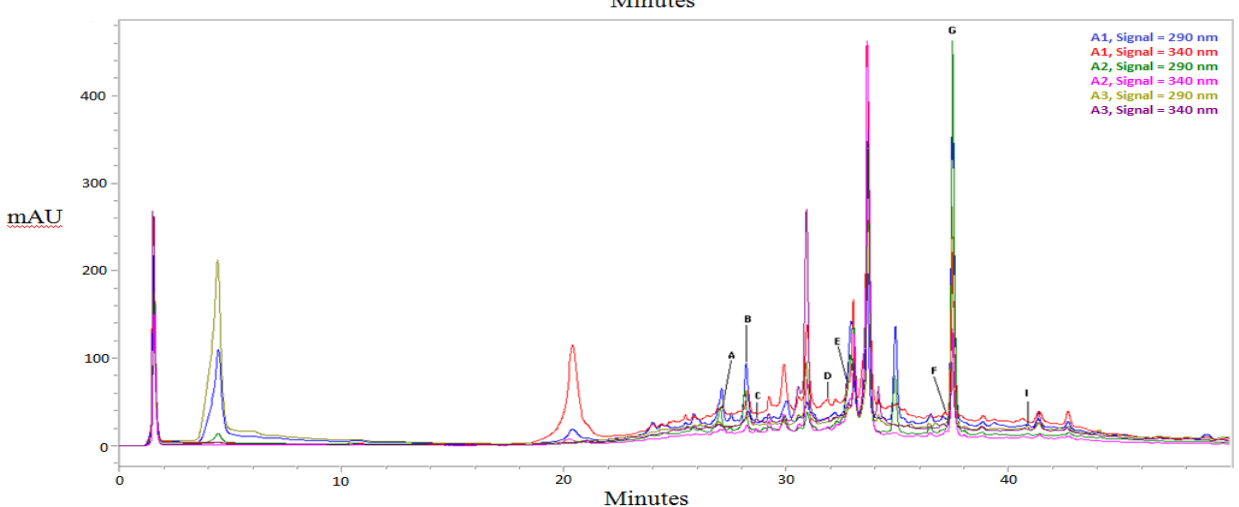

Fig. 2: HPLC chromatograms of Malaysian honeys: (a) Gelam, (b) Tualang and (c) Acacia at both $290 \mathrm{~nm}$ and $340 \mathrm{~nm}$. Phenolic compounds identified include: A ( $p$-coumaric acid), B (trans-ferulic acid), C (PGG), D (rutin), E (ellagic acid), F (quercetin), G (naringenin), H (hesperetin), I (kaempferol), and J (apigenin). 


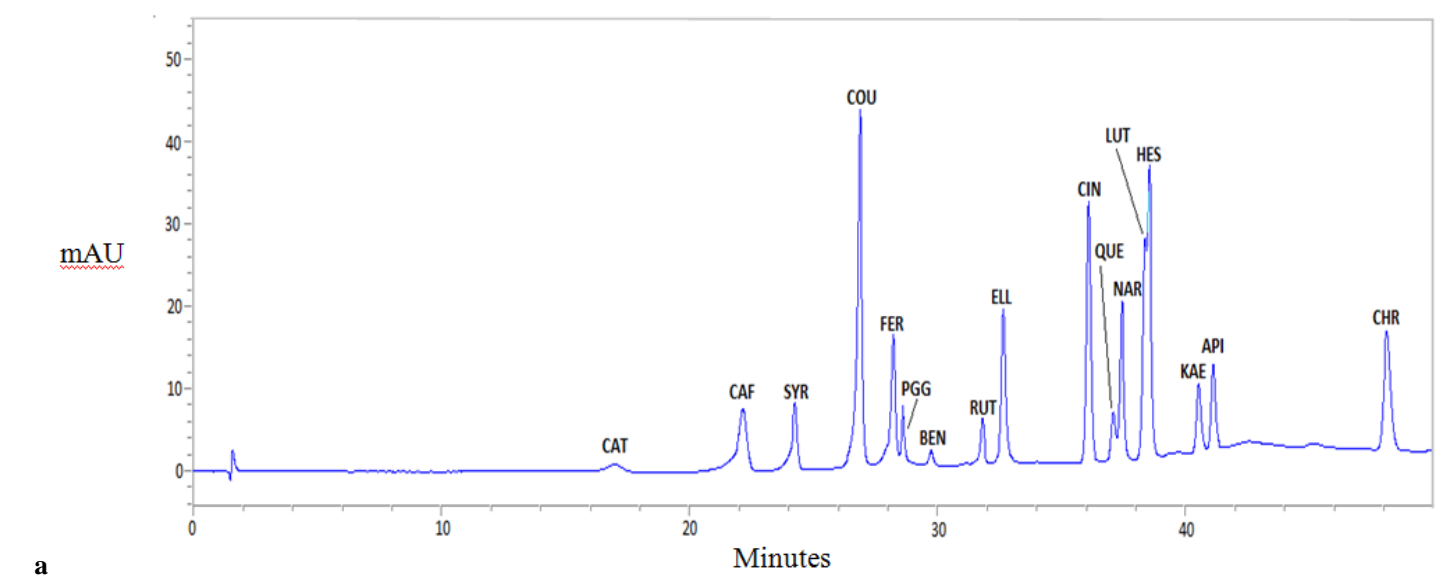

$\mathbf{a}$

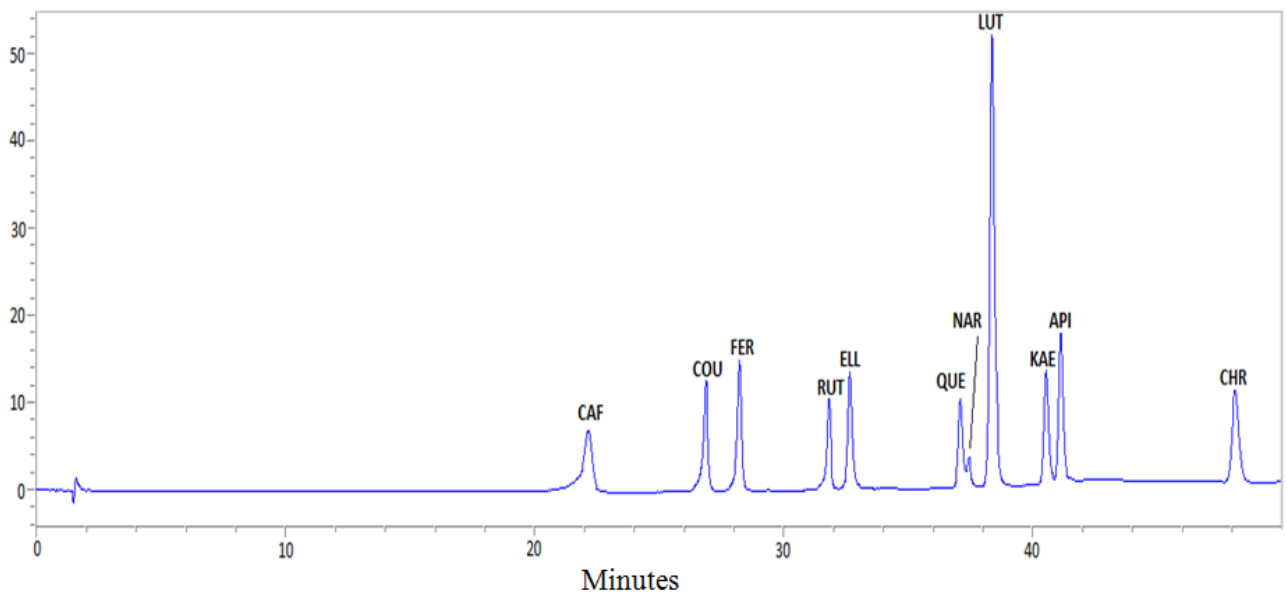

Fig. 3: HPLC chromatograms of polyphenolic standard compounds $(100 \mu \mathrm{g} / \mathrm{mL}$ ) at two wavelengths: (a) $290 \mathrm{~nm}$ and (b) $340 \mathrm{~nm}$. Phenolic compounds are: CAT (catechin), CAF (caffeic acid), SYR (syringic acid), COU ( $p$-coumaric acid), FER (trans-ferulic acid), PGG (penta- $O$-galloyl- $\beta$-D-glucose), BEN (benzoic acid), RUT (rutin hydrate), ELL (ellagic acid), CIN (trans-cinnamic acid), QUE (quercetin), NAR (naringenin), LUT (luteolin), HES (hesperetin), KAE (kaempferol), API (apigenin), and CHR (chrysin).

\section{DISCUSSION}

Table 3 shows the summary of polyphenolic compounds detected in current work with their anticarcinogenic mechanisms of action on various types of cancer cells. It was demonstrated earlier that quercetin, kaempferol, hesperetin, ellagic, ferulic and $p$-coumaric acids were present in Malaysian Gelam honey samples isolated using C18 silica SPE (Aljadi and Yusoff, 2003; Hussein et al., 2011; Wen et al., 2012), and Amberlite XAD-2 resin column chromatography (Kassim et al., 2010). All of these compounds were seen in Gelam honeys analysed in this study, except for quercetin (Table 2). In addition, naringenin, and apigenin have been detected in the Gelam honeys in this study, as well as in an earlier study performing C18 silica SPE (Khalil et al., 2011). Interestingly, rutin was not detected previously (Hussein et al., 2011; Wen et al., 2012) but was present in Gelam honey samples from this study. Gelam honeys exhibited several other polyphenols which are either not analysed or absent in current work, namely phenolic acids (gallic, benzoic, cinnamic, caffeic, chlorogenic) and flavonoids (myricetin, luteolin, chrysin and catechin) (Aljadi and Yusoff, 2003; Kassim et al., 2010; Hussein et al., 2011; Khalil et al., 2011; Wen et al., 2012).
In view of the presence of these polyphenols in Gelam honeys, it could be inferred that Malaysian Gelam honey is a promising chemopreventive agent. This claim is strongly supported by the study done by Jubri et al. (2012) whom demonstrated that Gelam honey reduced the proliferation rate of HepG2 liver cancer cells by inducing apoptosis at a low dose without affecting normal liver cells (WRL-68), which was observable through cell shrinkage. It was also found that Gelam honey suppressed growth of HT29 colon cancer cells by inducing DNA damage which leads to subsequent apoptosis, and suppressing inflammation (Wen et al., 2012). In fact, oxidative DNA damage with subsequent apoptosis has been associated with the possible mechanisms of action of chemotherapy drugs and chemopreventive herbs in killing cancer cells (Wen et al., 2012).

Tualang honey, a mixed floral deep jungle honey, has been extensively studied so far and proven to possess anticancer activities and a potential role as an adjuvant with current cancer drugs and chemotherapy. Malaysian Tualang honey has been shown to exhibit antiproliferative effect on oral squamous cell carcinomas (OSCC) and human osteosarcoma (HOS) cell lines by inducing early apoptosis in dose- and time-dependent manners (Ghashm et al., 2010). In addition, Tualang honey was found to 
induce apoptosis of human breast (MCF-7 and MDA-MB-231) and cervical (HeLa) cancer cell lines via depolarization of mitochondrial membrane (Fauzi et al., 2011). The study observed that Tualang honey displayed non-cytotoxic effect on normal breast epithelial cell lines (MCF-10A), suggesting that Tualang honey has an advantage over current anticancer agents. On top of that, an in vivo study revealed that Tualang honey exerted positive modulation effects on carcinogen 7,12-dimethylbenz $(\alpha)$ anthracene (DMBA)-induced breast cancers in rats in which; late development, smaller size and lesser number of tumor nodules (benign lesions) were the characteristics of Tualang honey-treated groups in comparison to control groups (Kadir et al., 2013). Thus, the study concluded that Tualang honey was a possibility when considering its use as a prophylactic or therapeutic agent to combat breast cancer growth or as an adjuvant to conventional chemotherapy (Kadir et al., 2013). A more recent study demonstrated that a combination of Tualang honey with Tamoxifen (TAM, a drug for breast cancer treatment) was more potent towards both MCF-7 and MDA-MB-231 breast cancer cell lines, suggesting that Tualang honey is a potential adjuvant to be used with TAM, provided that it reduces effective dose of TAM and simultaneously reduced TAM-induced adverse effects (Yaacob et al., 2013).

On the other hand, the contributory bioactive components that play vital roles in Tualang honey anticarcinogenic activities are yet not so clear. For that reason, the present and previous works have determined several polyphenols that might be responsible for Tualang honey anticarcinogenic properties. In this study, trans-ferulic acid, $p$-coumaric acid, ellagic acid, naringenin, hesperetin, kaempferol and apigenin were detected in Malaysian Tualang honey samples (Table 2). Previous studies have reported the presence of gallic, syringic, benzoic, $p$-coumaric, chlorogenic, caffeic and trans-cinnamic acids, naringenin, kaempferol, quercetin as well as catechin in Tualang honey samples (Khalil et al., 2011; Chua et al., 2013). Hesperetin in Tualang honey was first described in this study as it was not detected previously (Khalil et al., 2011). Besides, it was observed that Tualang honey exhibited less number of peaks of compounds as compared to Gelam and Acacia honeys (Figure 2). This finding suggests that the in vitro and in vivo anticancer effects of Tualang honeys could be partly attributed from their polyphenolic composition with contribution of other compounds as well. Several other compounds have been associated with honey's antioxidant properties including enzymes (glucose oxidase, catalase), ascorbic acid, organic acids, amino acids, carotenoid-like substances, and proteins (Jaganathan and Mandal, 2009).

In contrast, Malaysian Acacia honey (also known as Borneo tropical honey) has not yet gained much attention. A previous study reported that caffeic acid and catechin were the compounds detected in Acacia honey (Khalil et al., 2011). However, in comparison to the only data available (Khalil et al., 2011), findings of the current work exhibited that Malaysian Acacia honeys were found to be rich in polyphenols. To describe, eight out of ten analysed phenolic compounds were detected in Acacia honey samples examined in this work (Table 2). PGG, which is a naturally occurring gallotannin commonly found in medicinal herbs such as Paeonia lactiflora (Lee et al., 2004), and has been identified as a potential anticancer agent candidate (Lee et al., 2004; Zhang et al., 2009), was detected in Acacia honey samples in present work. This is the first time PGG is reported to be found in Malaysian honey. Therefore, presence of PGG together with other polyphenols in Malaysian Acacia honey supported its potential role in cancer chemoprevention. Previously, Italian Acacia honey has been demonstrated to induce cytotoxicity in human (A375) and murine (B16-F1) melanoma cell lines. The study affirmed that the observed effects of studied Acacia honey was mainly due to the presence of chrysin (5,7-dihydroxyflavone) (Pichichero et al., 2010). However, present study did not detect chrysin in analysed Acacia honey samples.

Detection of phenolic compounds was done using UV absorption spectra monitoring at $290 \mathrm{~nm}$ and $340 \mathrm{~nm}$, taking into account that the majority of honey phenolics and flavonoids exhibit maximum UV absorption around these two wavelengths (Martos et al., 1997). In comparison to the findings obtained by Hussein et al. (2011), it was observed that modification made for HPLC analysis in current work has managed to obtain wellseparated peaks of compounds of interest within a shorter run time (Figure 3). The reported study performed an analysis in 73 minutes while current work completed one analysis in 60 minutes. Total of seventeen authentic standard compounds have been separated using the HPLC-DAD system in the present study (Figure 3). However, only ten of these compounds were present in both the analysed honey samples and exhibited anticancer activity (Table 2 ). Therefore, this study is focusing on only these ten compounds. Additionally, the current work also successfully detects compounds with high peak intensity which is observable from the chromatograms. Previous study by Kassim et al. (2010) also showed peaks of compounds at higher intensities, but the amount of honey sample used for analysis was $100 \mathrm{~g}$, which is 20 times higher than in the current work. Conversely, lesser peak intensities were demonstrated in the study by Khalil et al. (2011) with the same amount of honey sample used as in present study $(5 \mathrm{~g})$.

Still, direct comparisons between current findings and reported studies on phenolic composition of Malaysian honeys were limited due to different samples used, as well as extraction, isolation and HPLC procedures. Unavailability of reference standard compounds for comparison also limits the identification of all peaks of compounds that appear in the chromatograms. However, this study suggests that the presence of similar bioactive phenolic compounds in the same type of honey, despite the different extraction, isolation and HPLC procedures applied, could be regarded as a way of confirming the polyphenolic profile of that type of honey. Furthermore, it should be emphasized that similar types of honey in terms of floral source may vary greatly in phenolic compositions and proportions depending on geographical location, climatic conditions and bee species. 


\section{CONCLUSION}

The presence of identified phenolic compounds in Malaysian Gelam, Tualang and Acacia honeys at varying degrees is therefore supporting their prospective roles as natural cancer chemopreventive agents. From the present findings, it could be deduced that most of the polyphenols found in analysed Malaysian honeys have the ability to induce apoptosis of cancer cells. This is coherent with the reported observations where induction of apoptosis was observed when Malaysian honeys were introduced to cancer cells. It is suggested that combination of honey with cancer drugs during chemotherapy could help to reduce the effective dose and side effects of drugs, as well as inhibit progression of cancer cells. Hence, the results of present study encourage more in vivo studies and clinical trials to be conducted to further evaluate the efficacy of Malaysian honeys in cancer chemoprevention.

\section{ACKNOWLEDGEMENT}

We gratefully acknowledge the financial support from the Ministry of Higher Education Malaysia and research university grant from Universiti Teknologi Malaysia (PY/2014/03300 [7845.4F581]). We would like to extend our sincere appreciation to Prof. Siti Amrah Sulaiman and Dr. Mahaneem Mohamed (Universiti Sains Malaysia) for their thoughts, as well as Faculty of Biosciences and Medical Engineering, Universiti Teknologi Malaysia for the provided equipments. The authors acknowledge Mr. Willy (Sabah Rural Development Corporation) and $\mathrm{Mr}$. Ibrahim (Terengganu Honey Collector Corporation) for supplying honey samples for this study. The first author expresses her thankfulness to Universiti Teknologi Malaysia for the awarded Zamalah Scholarship.

\section{REFERENCES}

Abubakar MB, Abdullah WZ, Sulaiman SA, Suen AB. A review of molecular mechanisms of the anti-leukemic effects of phenolic compounds in honey. Int J Mol Sci, 2012; 13: 15054-15073.

Aljadi AM, Yusoff KM. Isolation and identification of phenolic acids in Malaysian honey with antibacterial properties. Turkish J Med Sci, 2003; 33: 229-236.

Alshatwi AA, Ramesh E, Periasamy VS, Subash-Babu P. The apoptotic effect of hesperetin on human cervical cancer cells is mediated through cell cycle arrest, death receptor, and mitochondrial pathways. Fundam Clin Pharmacol, 2013; 27(6): 581-592.

Bestwick CS, Milne L, Duthie SJ. Kaempferol induced inhibition of HL-60 cell growth results from a heterogeneous response, dominated by cell cycle alterations. Chem Biol Interact, 2007; 170: $76-85$

Chai Y, Lee H-J, Shaik AA, Nkhata K, Xing C, Zhang J, Jeong S-J, Kim S-H, Lü J. Penta- $O$-galloyl- $\beta$-D-glucose induces $\mathrm{G}_{1}$ arrest and DNA replicative S-phase arrest independently of P21 cyclin-dependent kinase inhibitor 1A, P27 cyclin-dependent kinase inhibitor 1B and P53 in human breast cancer cells and is orally active against triple-negative xenograft growth. Breast Cancer Res, 2010; 12(R67): 1-11.

Chen H, Miao Q, Geng M, Liu J, Hu Y, Tian L, Pan J, Yang Y. Anti-tumor effect of rutin on human neuroblastoma cell lines through inducing G2/M cell cycle arrest and promoting apoptosis. Sci World J, 2013; 269165: 1-8.
Chua LS, Rahaman NLA, Adnan NA, Tan TTE. Antioxidant activity of three honey samples in relation with their biochemical components. J Anal Methods Chem, 2013; 313798: 1-8.

Erejuwa OO, Sulaiman SA, Wahab MSA. Effects of honey and its mechanisms of action on the development and progression of cancer. Molecules, 2014; 19: 2497-2522.

Fauzi AN, Norazmi MN, Yaacob NS. Tualang honey induces apoptosis and disrupts the mitochondrial membrane potential of human breast and cervical cancer cell lines. Food Chem Toxicol, 2011; 49: 871878.

Ferreres F, Tomás-Barberán F, Soler C, García-Viguera C, Ortiz A, Tomás-Lorente F. A simple extractive technique for honey flavonoid HPLC analysis. Apidologie, 1994; 25: 21-30.

Fresco P, Borges F, Diniz C, Marques MPM. New insights on the anticancer properties of dietary polyphenols. Med Res Rev, 2006; 26(6): 747-766.

Gao K, Henning SM, Niu Y, Youssefian AA, Seeram NP, Xu A, Heber D. The citrus flavonoid naringenin stimulates DNA repair in prostate cancer cells. J Nutr Biochem, 2006; 17(2): 89-95.

Ghashm AA, Othman NH, Khattak MN, Ismail NM, Saini R. Antiproliferative effect of Tualang honey on oral squamous cell carcinoma and osteosarcoma cell lines. BMC Complement Altern Med, 2010; 10(49): $1-8$.

Gonzalez-Mejia ME, Voss OH, Murnan EJ, Doseff AI. Apigenin-induced apoptosis of leukemia cells is mediated by a bimodal and differentially regulated residue-specific phosphorylation of heat-shock protein-27. Cell Death Dis, 2010; 1(e64): 1-9.

Hagiwara Y, Kasukabe T, Kaneko Y, Niitsu N, Okabe-Kado J. Ellagic acid, a natural polyphenolic compound, induces apoptosis and potentiates retinoic acid-induced differentiation of human leukemia HL-60 cells. Int J Hematol, 2010; 92: 136-143.

Hu H, Lee H-J, Jiang C, Zhang J, Wang L, Zhao Y, Xiang Q, Lee E-O, Kim S-H, Lü J. Penta-1,2,3,4,6- $O$-galloyl- $\beta$-D-glucose induces p53 and inhibits STAT3 in prostate cancer cells in vitro and suppresses prostate xenograft tumor growth in vivo. Mol Cancer Ther, 2008; 7: 26812691.

Hussein SZ, Yusoff KM, Makpol S, Yusof YAM. Antioxidant capacities and total phenolic contents increase with gamma irradiation in two types of Malaysian honey. Molecules, 2011; 16: 6378-6395.

Jaganathan SK, Mandal M. Antiproliferative effects of honey and of its polyphenols: A review. J Biomed Biotechnol, 2009; 830616: 1 13.

Jaganathan SK, Supriyanto E, Mandal M. Events associated with apoptotic effect of $p$-Coumaric acid in HCT-15 colon cancer cells. World J Gastroenterol, 2013; 19(43): 7726-7734.

Jubri Z, Narayanan NNN, Karim NA, Ngah WZW. Antiproliferative activity and apoptosis induction by Gelam honey on liver cancer cell line. IJAST, 2012; 2(4): 135-141.

Kadir EA, Sulaiman SA, Yahya NK, Othman NH. Inhibitory effects of Tualang honey on experimental breast cancer in rats: A preliminary study. Asian Pacific J Cancer Prev, 2013; 14(4): 2249-2254.

Kampa M, Alexaki V-I, Notas G, Nifli A-P, Nistikaki A, Hatzoglou A, Bakogeorgou E, Kouimtzoglou E, Blekas G, Boskou D, Gravanis A, Castanas E. Antiproliferative and apoptotic effects of selective phenolic acids on T47D human breast cancer cells: potential mechanisms of action. Breast Cancer Res, 2004; 6: R63-R74.

Kassim M, Achoui M, Mustafa MR, Mohd MA, Yusoff KM. Ellagic acid, phenolic acids, and flavonoids in Malaysian honey extracts demonstrate in vitro anti-inflammatory activity. Nutr Res, 2010; 30: 650659.

Khalil MI, Alam N, Moniruzzaman M, Sulaiman SA, Gan SH. Phenolic acid composition and antioxidant properties of Malaysian honeys. J Food Sci, 2011; 76(6): 921-928.

Lee SJ, Lee HM, Ji ST, Lee SR, Mar W, Gho YS. 1,2,3,4,6Penta- $O$-galloyl-beta-D-glucose blocks endothelial cell growth and tube formation through inhibition of VEGF binding to VEGF receptor. Cancer Lett, 2004; 208: 89-94. 
Lee T-J, Kim OH, Kim YH, Lim JH, Kim S, Park J-W, Kwon TK. Quercetin arrests G2/M phase and induces caspase-dependent cell death in U937 cells. Cancer Lett, 2006; 240: 234-242.

Luo H, Jiang B-H, King SM, Chen YC. Inhibition of cell growth and VEGF expression in ovarian cancer cells by flavonoids. Nutr Cancer, 2008; 60(6): 800-809.

Martos I, Cossentini M, Ferreres F, Tomas-Barberan FA. Flavonoid composition of Tunisian honeys and propolis. J Agric Food Chem, 1997; 45(8): 2824-2829.

Michalkiewicz A, Biesaga M, Pyrzynska K. Solid-phase extraction procedure for determination of phenolic acids and some flavonols in honey. J Chromatogr A, 2008; 1187: 18-24.

Othman NH. Honey and cancer: Sustainable inverse relationship particularly for developing nations - A review. Evid Based Complement Alternat Med, 2012; 410406: 1-10.

Pichichero E, Cicconi R, Mattei M, Muzi MG, Canini A. Acacia honey and chrysin reduce proliferation of melanoma cells through alterations in cell cycle progression. Int J Oncol, 2010; 37: $973-$ 981.

Simon JJ. Phytochemicals \& cancer. J Chiropr Med, 2002; 1(3):

91-96.

Sporn MB. Approaches to prevention of epithelial cancer during the preneoplastic period. Cancer Res, 1976; 36: 2699-2702.

Stalikas CD. Extraction, separation, and detection methods for phenolic acids and flavonoids. J Sep Sci, 2007; 30: 3268-3295.

Surh YJ. Cancer chemoprevention with dietary phytochemicals. Nat Rev Cancer, 2003; 3: 768-780.

Swellam T, Miyanaga N, Onozawa M, Hattori K, Kawai K, Shimazui T, Akaza H. Antineoplastic activity of honey in an experimental bladder cancer implantation model: In vivo and in vitro studies. Int J Urol, 2003; 10: 213-219.
Wen CTP, Hussein SZ, Abdullah S, Karim NA, Makpol S, Yusof YAM. Gelam and Nenas honeys inhibit proliferation of HT 29 colon cancer cells by inducing DNA damage and apoptosis while suppressing inflammation. Asian Pacific J Cancer Prev, 2012: 13: $1605-$ 1610.

Yaacob NS, Nengsih A, Norazmi MN. Tualang honey promotes apoptotic cell death induced by tamoxifen in breast cancer cell lines. Evid Based Complement Alternat Med, 2013; 989841: 1-9.

Yao L, Datta N, Tomás-Barberán FA, Ferreres F, Martos I, Singanusong R. Flavonoids, phenolic acids and abscisic acid in Australian and New Zealand Leptospermum honeys. Food Chem, 2003; 81: $159-168$

Zhang J, Li L, Kim S-H, Hagerman AE, Lü J. Anti-cancer, antidiabetic and other pharmacologic and biological activities of pentagalloyl-glucose. Pharm Res, 2009; 26: 2066-2093.

\section{How to cite this article:}

Norjihada Izzah Ismail, Mohammed Rafiq Abdul Kadir, Razauden Mohamed Zulkifli. Isolation and Identification of Potential Antineoplastic Bioactive Phenolic Compounds in Malaysian Honeys. J App Pharm Sci, 2015; 5 (10): 059-066. 